\title{
Nevirapine-Induced Side Effects in Pregnant Women - Experience of a Brazilian University Hospital
}

\author{
William Kondo, Elaine Aparecida Carraro, Elaine Prandel, Josiane Mourão Dias, Juliane Perini, Rodolfo Lara de Macedo, \\ Taynah Cristina Cornelsen, Renato Sbalquiero and Maria das Graças Sasaki \\ Department of Gynecology and Obstetrics, Clinics Hospital of the Federal University of Parana; Curitiba, PR, Brazil
}

\begin{abstract}
Nevirapine-based therapy is associated with increased frequency of adverse events among HIV-infected pregnant women. The aim of this article was to evaluate the incidence of adverse effects in HIV-infected women who started nevirapine during pregnancy. A retrospective study was performed in our center between January 2003 and December 2006 analyzing all women prescribed nevirapine during pregnancy. Women presenting any risk factor for hepatotoxicity were excluded from the analysis. Patients were divided into two groups according to the presence or absence of adverse effects, and a correlation to CD4 counts was performed. Liver function abnormality was graded according to the Division of AIDS toxicity guidelines. A total of 170 women initiated nevirapine during pregnancy, but only 133 were included in the study. Twenty-seven women $\mathbf{( 2 0 . 3 \%}$ ) presented adverse effects, skin rash accounting for $\mathbf{7 7 . 8 \%}$ (21/27 women) and liver function abnormalities for $22.2 \%(6 / 27)$ of the cases. Baseline CD4 counts, viral loads and transaminases were similar in both groups. All nevirapine side effects were developed in less than seven weeks. Four of 31 women with CD4 counts $<250$ cells/ $\mu \mathrm{L}(12.9 \%)$ and 23 of 102 women with CD4 counts $\geq 250$ cells/ $\mu \mathrm{L}$ (22.5\%) developed adverse events. All patients who experienced hepatotoxicity had pretreatment CD4 counts $\geq 250$ cells/ $\mu \mathrm{L}$. The incidence of adverse events with nevirapine in our study was high, but most of them were cutaneous. There was no correlation between high CD4 counts and adverse events when analyzing both cutaneous and hepatic reactions; nevertheless, hepatotoxicity occurred only in pregnant women with CD4 counts $\geq 250$ cells $/ \mu \mathrm{L}$.

Key-Words: Hepatotoxicity, HIV-1, nevirapine, pregnancy, toxicity.
\end{abstract}

Potent combined antiretroviral therapy is commonly prescribed for pregnant women to reduce maternal viral load and thereby minimize the risk of mother-to-child transmission of HIV-1, as well as to treat maternal HIV-1 disease when indicated [1-4].

In accordance with the Brazilian guidelines for management of HIV-1 in pregnancy, all pregnant HIV-infected women during the prenatal care are offered either zidovudine or a triple antiretroviral regimen, usually including nevirapine or nelfinavir, depending on their CD4 cell count and HIV-1 virus load. Antiretrovirals are provided either as treatment or as prophylaxis for HIV-positive patients, with the goal of decreasing viral loads to less than 1,000 copies $/ \mathrm{mL}$ at delivery $[4,5]$. The choice between nelfinavir and nevirapine is based on weeks of gestation, immune status, viral load and adhesion to treatment and clinical follow-up [5].

Nevirapine, a potent non-nucleoside reverse transcriptase inhibitor, is well absorbed with oral dosing and distributes readily across the placenta. It reaches maximal plasma concentrations three hours after a single oral dose of $200 \mathrm{mg}$, and has a relatively low clearance, allowing twice-a-day administration [6]. The favorable pharmacokinetic profile of nevirapine permits a simplified dosage and inexpensive regimen to prevent perinatal transmission, especially in developing countries $[7,8]$.

Recently, a number of studies have raised the issue of the toxicity of nevirapine administered during pregnancy to HIVReceived on 10 July 2007; revised 6 November 2007.

Address for correspondence: Dr. William Kondo. Av. Getulio Vargas 3163, ap 21. CEP 80240-041. Curitiba - PR. Telephone number: (41) 9222-1065. E-mail: williamkondo@yahoo.com.

The Brazilian Journal of Infectious Diseases 2007;11(6):544-548. (C) 2007 by The Brazilian Journal of Infectious Diseases and Contexto Publishing. All rights reserved. 1-positive women [1,9-14]. Rash is the most common cutaneous side effect of nevirapine, and the incidence has varied across different studies [15]. It usually appears in the first four weeks and may result in the development of StevensJohnson syndrome or toxic epidermal necrolysis [16]. Nevirapine may also cause hepatic toxicity ranging from asymptomatic hepatitis to acute liver necrosis and death $[9,10,17,18]$.

In order to assess the potential side effects of nevirapinecontaining regimens in our center, we conducted a retrospective study in our database including treatment-naive HIV-1-infected pregnant women who started nevirapine during pregnancy.

\section{Material and Methods}

A retrospective study was undertaken to determine the incidence of side effects associated with nevirapine use in pregnancy among all HIV-1-infected pregnant women who started this medication during pregnancy and were treated at our HIV High-Risk Pregnancy Outpatient Facility between January 2003 and December 2006. The study protocol was previously approved by the Institutional Review Board of the study hospital.

All patients have had the diagnosis of HIV infection confirmed according to the Brazilian Ministry of Health protocol [19].

Data were collected reviewing clinical charts and included: clinical history, demographic and social data, including alcohol and illicit drug abuse. Interval history, physical exam, concomitant medications, side effects (rash, fever, pruritus, jaundice, choluria, acholia, and others) and the need of changing medication were reviewed at each prenatal visit. All women with a CD4 count under 200 cells/ $\mu \mathrm{L}$ received cotrimoxazole as prophylaxis. 
Laboratory evaluations included complete blood counts, biochemistry panel with alanine aminotransferase (ALT) and aspartate aminotransferase (AST) at baseline and if needed thereafter, hepatitis B virus and hepatitis $\mathrm{C}$ virus serologies, as well as CD4 cell counts and plasma HIV-1 viral load.

The study group consisted of all treatment-naive HIV-1infected pregnant women who were treated with regimens containing nevirapine during pregnancy for more than seven days and delivered at more than 20 weeks of gestation. There was no restriction to CD4 cell count at study entry. Exclusion criteria included: (1) women who started nevirapine before pregnancy, (2) patients with abnormal baseline liver enzymes (alanine aminotransferase greater than 2.5 times the upper limit of normal), (3) women with incomplete liver biochemistry data (fewer than one pretreatment and two on-treatment values), (4) positive serology for hepatitis B or C, and (5) IV drug abuse.

Nevirapine was always prescribed associated to zidovudine and lamivudine, at a dose of $200 \mathrm{mg} /$ day for the first 14 days. If no cutaneous manifestation developed after the first two weeks, full dose (200 mg twice a day) was started. Rigorous control of liver function during the first 18 weeks was performed checking liver enzymes twice a month. After this period, liver biochemistry was monthly checked [5].

The incidence of cutaneous and/or hepatic toxicity was estimated according to the National Institute of Allergy and Infectious Diseases Division of AIDS toxicity grading scales. Severity of ALT and AST levels were graded in accordance with the National Institute of Allergy and Infectious Diseases toxicity guidelines as follows [1,3,20]:

- Grade $0 \leq 1.25$ times the upper limit of normal;

- Grade $1=1.25-2.5$ times the upper limit of normal (mild hepatotoxicity);

- Grade 2 =2.5-5.0 times the upper limit of normal (mild hepatotoxicity);

- Grade 3 =5.0-10.0 times the upper limit of normal (severe hepatotoxicity);

- Grade $4 \geq 10$ times the upper limit of normal (severe hepatotoxicity).

According to Brazilian guidelines, nevirapine can be continued in cases of (1) moderate rash with no constitutional symptoms and (2) rash with no liver enzymes increase. The medication must be suspended permanently in cases of (1) severe rash or constitutional symptoms or organ dysfunction and (2) presence of rash associated with increase in transaminase measurements [5]. The first choice drug to replace nevirapine during pregnancy is nelfinavir.

Patients were divided into two groups: those with nevirapine-induced side effects and those without any reaction. Patients were also stratified by CD4 cell counts of either less than or equal to or greater than 250 cells $/ \mu \mathrm{L}$ and by the gestational age at the start of nevirapine-based regimens for data analysis. Laboratory results were compared between baseline (before nevirapine-based antiretroviral therapy) and after initiation of therapy. Statistical analysis was carried out using STATISTICA 5.5 and variables were analyzed using the Fisher exact test or Student's t test. Statistical significance was set at $\mathrm{p} \leq 0.05$.

\section{Results}

During the study period, a total of 170 women were identified using nevirapine as part of combination antiretroviral therapy in pregnancy, of whom 133 were eligible for the analysis. The remaining 37 women did not meet the criteria described before. Fourteen women were excluded because they had been using nevirapine before becoming pregnant, seven were positive for hepatitis $\mathrm{C}$, seven were positive for hepatitis B surface antigen, four were IV drug users, three presented abnormal baseline liver enzymes, and two had incomplete data for analysis.

Twenty-seven women (20.3\%) presented cutaneous and/ or hepatic toxicity. The baseline clinical characteristics in our patients are shown in Table 1.

Baseline CD4 counts, viral loads and transaminases subsets were available in all patients and there were no statistically significant differences in baseline characteristics between women with and without nevirapine adverse events. Mean absolute CD 4 cell counts were 455.9 and 416.1 cells $/ \mu \mathrm{L}$ in women with and without side effects, respectively, and did not differ significantly between both groups $(\mathrm{p}=0.41)$. Time of exposure to nevirapine varied from seven to 189 days, mean of 26.6 days in women with side effects and 101.5 days in patients without adverse effects $(\mathrm{p}<0.01)$.

Table 2 demonstrates the correlation between CD4 cell counts and the presence of side effects. Four of 31 women with CD4 counts $<250$ cells/ $\mu \mathrm{L}(12.9 \%)$ and 23 of 102 women with CD4 counts $\geq 250$ cells $/ \mu \mathrm{L}(22.5 \%)$ developed side effects, with no significant difference between both groups $(\mathrm{p}=0.24)$.

Time to onset of side effects ranged from seven to 49 days (mean $25.3 \pm 11.4$ days) after nevirapine initiation. Skin rash accounted for $77.8 \%$ of toxicities (21/27 women), and were seen in $15.8 \%$ of all patients receiving nevirapine. Liver function abnormalities were noted in $22.2 \%$ of women exhibiting toxicities $(6 / 27)$ and in $4.5 \%$ of the total number of patients receiving nevirapine. No woman had both skin rash and liver abnormality (Table 3). Grade 1, 2 and 3 hepatotoxicity appeared in one, three and two women respectively. Patients with hepatotoxicity grade 2 and 3 were admitted to the hospital and after discontinuation of nevirapine, all the affected individuals rapidly improved.

\section{Discussion}

Asymptomatic increases in AST or ALT levels of more than five times the upper limit of normal occurred in about $9 \%$ of patients taking nevirapine (as compared with $6 \%$ of controls). Symptomatic hepatitis was observed in about $4 \%$ of patients treated with the drug [21]. Time of exposure to nevirapine $[10,17,18]$, higher CD4 cell counts $(\geq 250$ cells $/ \mu \mathrm{L})$ $[1,9,14,19,22]$, co-infection with hepatitis B or C $[10,14,17$ - 
Table 1. Clinical characteristics of 133 HIV-infected pregnant women using nevirapine

\begin{tabular}{|c|c|c|c|c|}
\hline & $\begin{array}{l}\text { Side effects } \\
\quad(\mathbf{n}=\mathbf{2 7})\end{array}$ & $\begin{array}{l}\text { No side effects } \\
\quad(n=106)\end{array}$ & $\begin{array}{c}\text { Total } \\
(\mathbf{n}=\mathbf{1 3 3})\end{array}$ & p value \\
\hline Age (years) [mean (range)] & $30.4 \pm 6.4$ & $27.5 \pm 6.1$ & $28.1 \pm 6.3(14-43)$ & 0.03 \\
\hline $\begin{array}{l}\text { Duration of nevirapine exposure (weeks) } \\
\text { [mean (range)] }\end{array}$ & $3.8 \pm 1.8$ & $14.5 \pm 6.8$ & $12.3 \pm 7.5(1-27)$ & $<0.01$ \\
\hline $\begin{array}{l}\text { Weeks' gestation at medication start } \\
\text { [mean (range)] }\end{array}$ & $22.7 \pm 7.8$ & $24.5 \pm 7$ & $24.1 \pm 7.2(10-37)$ & 0.25 \\
\hline Weeks of follow-up [mean (range)] & $15.8 \pm 7.9$ & $14.5 \pm 7$ & $14.8 \pm 7(1-27)$ & 0.38 \\
\hline $\begin{array}{l}\text { Entry viral load (copies/mL) } \\
\text { [mean (range)] }\end{array}$ & $24,192.1 \pm 33,603.4$ & $24,702.4 \pm 44,376.2$ & 24,602.7 (0-240,000) & 0.95 \\
\hline $\begin{array}{l}\text { Entry CD4 count }(\text { cells } / \mu \mathrm{L}) \\
{[\text { mean (range)] }}\end{array}$ & $455.9 \pm 217.1$ & $416.1 \pm 216.8$ & $423.8 \pm 216.6(43-1160)$ & 0.41 \\
\hline Entry AST & $19.3 \pm 5.9$ & $20.6 \pm 5.8$ & $20.4 \pm 5.8(10-40)$ & 0.5 \\
\hline Entry ALT & $15.5 \pm 8.8$ & $15.6 \pm 5.5$ & $15.4 \pm 6.1(6-35)$ & 0.7 \\
\hline
\end{tabular}

Table 2. Correlation between CD4 cell counts and development of side effects

\begin{tabular}{lcc}
\hline & Side effects & No side effects \\
\hline $\mathrm{CD} 4<250$ cells $/ \mu \mathrm{L}$ & 4 & 27 \\
$\mathrm{CD} 4 \geq 250 \mathrm{cells} / \mu \mathrm{L}$ & 23 & 79 \\
\hline
\end{tabular}

Table 3. Adverse events in women on nevirapine therapy

\begin{tabular}{lccc}
\hline & $\begin{array}{c}\text { CD4 }<\mathbf{2 5 0} \\
\text { cells } / \boldsymbol{\mu L}\end{array}$ & $\begin{array}{c}\text { CD4 } \mathbf{2 5 0} \\
\text { cells } / \boldsymbol{\mu L}\end{array}$ & Total \\
\hline Rash & 4 & 17 & 21 \\
Hepatotoxicity & & & \\
$\quad$ Grade 1 & 0 & 1 & 1 \\
Grade 2 & 0 & 3 & 3 \\
Grade 3 & 0 & 2 & 2 \\
Grade 4 & 0 & 0 & 0 \\
\hline
\end{tabular}

19,23], elevated baseline liver enzymes [10,14,22], and alcohol/ drug abuse $[18,23]$ have all been associated with nevirapine toxicity. In our cohort we excluded all HIV-infected pregnant women with any of these risk factors for toxicity to better evaluate the role of nevirapine in drug-induced adverse events.

Higher CD4 cell counts have been associated with increased risk of severe nevirapine-associated skin rash [15]. In controlled clinical trials, clinical hepatic events, regardless of severity, occurred in $4 \%$ (ranged from 2.5 to $11 \%$ ) of patients who received nevirapine; however, the risk of nevirapineassociated liver failure or hepatic mortality has been lower, ranging between 0.04 and $0.4 \%$ [22,24]. Severe or life threatening rash occurs in approximately $2 \%$ of patients receiving nevirapine [24]. The recent cohort of Jamisse et $\mathrm{al}^{28}$ demonstrated that severe hepatotoxicity from nevirapinecontaining highly active antiretroviral treatment was more common at higher CD4 counts ( $6 \%$ vs $0 \%$ among women with CD 4 counts $\geq 250$ cells $/ \mu \mathrm{L}$ and $<250$ cells $/ \mu \mathrm{L}$, respectively).
Nevertheless, in the study of Joao et al. [4], only CD4 counts above 600 cells $/ \mu \mathrm{L}$ showed a significant increase for the risk of toxicity.

Severe, life-threatening, and in some cases, fatal hepatotoxicity, including fulminant and cholestatic hepatitis, hepatic necrosis, and hepatic failure, and severe, lifethreatening hypersensitivity skin reactions, including StevensJohnson syndrome, have been reported in HIV-infected patients receiving nevirapine in combination with other drugs for treatment of HIV disease and in a small number of individuals receiving nevirapine as part of a combination regimen for post-exposure prophylaxis of nosocomial or sexual HIV exposure [25]. These toxicities have also been reported in HIV-infected pregnant women taking highly active antiretroviral treatment containing nevirapine for prevention of perinatal transmission [2-4,26-29]. The greatest risk of severe rash or hepatic events occurs during the first six weeks of therapy $[19,27]$, although the risk of toxicity continues past this period and monitoring should continue at frequent intervals. Liver failure sometimes progresses despite discontinuation of the drug [27].

To date there have been reported at least eight cases of fulminant hepatitis culminating in maternal death associated with nevirapine as part of combination antiretroviral therapy in pregnancy $[1,30,31]$. The common features of all six cases reported by Hitti et al. [1] included fulminant hepatic failure presenting four to five weeks after starting nevirapine-based antiretroviral therapy, in antiretroviral-naive subjects with previously normal ALT and no history of hepatitis B or C. All of them occurred in women with a baseline CD 4 cell count greater than 250 cells $/ \mu \mathrm{L}$. Furthermore, in these cases, hepatitis progressed rapidly to hepatic failure and death despite discontinuation of nevirapine and close clinical and laboratory monitoring.

The incidence rate of adverse effects of nevirapinecontaining regimen was $20.3 \%$ in our series, and they were frequently self-limiting. Time to development of adverse effect was seven to 49 days, mean of 25 days. All nevirapine side 
effects developed in less than seven weeks, as observed in other cohorts of pregnant women $[1,4,29]$. While a grade 3 elevation of ALT and AST levels was detected in $1.5 \%$ (two cases) of women using a nevirapine-containing regimen, these elevations resulted in no significant clinical hepatotoxicity. We also observed $2.3 \%$ (three cases) and $0.75 \%$ (one case) of grade 2 and 1 hepatotoxicity, respectively. Patients with grade 2 and 3 hepatotoxicity were hospitalized and all cases resulted in transient elevations of transaminase levels, which had decreased again by the next check-up when nevirapine was stopped. All cases of transaminase elevation occurred among women with CD4 counts superior to 250 cells/ $\mu \mathrm{L}$ in our study. The remaining 21 patients $(15.75 \%)$ developed skin rash along with or without pruritus, with spontaneous regression after discontinuing medication.

Baseline CD4 cell counts and viral load did not differ significantly between our patients with and without side effects. Adverse effects were observed in $22.5 \%$ and $12.9 \%$ of patients with CD4 counts $\geq 250$ cells $/ \mu \mathrm{L}$ and $<250$ cells $/ \mu \mathrm{L}$, respectively, but this difference did not reach any statistical significance $(p=0.24)$. Similarly, Kramer et al. [32] found no significant differences to CD4 cell counts among pregnant women with and without nevirapine toxicity. A recent publication evaluated $235 \mathrm{HIV}$-infected pregnant women on nevirapine-based antiretroviral therapy concluding that the medication is well-tolerated and CD4 count may be less predictive of toxicity in pregnancy [33]. Similar findings had already been published by Marazzi et al. [34] in African pregnant women using nevirapine-based antiretroviral therapy.

It is interesting that our data did not confirm an association between high CD4 cell counts and nevirapine-induced side effects when considering both cutaneous and hepatic reactions. However, when we considered only hepatotoxicity, we observed that all cases of alterations in liver enzymes occurred in patients with CD4 cells count $\geq 250$ cells $/ \mu \mathrm{L}$, confirming the correlation between high CD4 counts and hepatic toxicity. This observation is compatible with the hypothesis that hepatotoxicity is caused by an immunemediated toxic effect on the liver, which is more rapid when the immune system itself is less compromised.

It is unknown if pregnancy increases the risk of hepatotoxicity in women receiving nevirapine or other antiretroviral drugs $[30,31]$. Because pregnancy itself can mimic some of the early symptoms of hepatotoxicity (intrahepatic cholestasis, acute fatty liver, preeclampsia and eclampsia), health care providers caring for women receiving nevirapine during pregnancy should be aware of this potential complication and conduct frequent and careful monitoring of clinical symptoms and hepatic transaminases (i.e., alanine aminotransferase, ALT, and aspartate aminotransferase, AST), particularly during the first 18 weeks of therapy [5].

\section{Conclusions}

We observed a high incidence of side effects related to nevirapine-based antiretroviral therapy in our patients, most of them presenting only skin rash with no transaminase elevation. There was no correlation between CD4 cells count and nevirapine-induced side effects when both cutaneous and hepatic events were analyzed; however, all cases of hepatic toxicity occurred in patients with CD4 cells count $\geq 250$ cells $/ \mu \mathrm{L}$. These data led us to change the management of HIV in pregnancy in our center, and nevirapine as part of combination antiretroviral therapy in pregnancy is no longer recommended as the first choice when the primary indication for therapy is reduction of mother-to-child transmission of HIV. Nowadays we prefer to start a nelfinavir-based therapy and we reserve nevirapine to those patients with nelfinavir side effects.

\section{References}

1. Hitti J., Frenkel L.M., Stek A.M., et al. Maternal toxicity with continuous nevirapine in pregnancy: results from PACTG 1022. J Acquir Immune Defic Syndr 2004;36:772-6.

2. Lyons F., Hopkins S., Kelleher B., et al. Maternal hepatotoxicity with nevirapine as part of combination antiretroviral therapy in pregnancy. HIV Med 2006; 7:255-60.

3. Joy S., Poi M., Hughes L., et al. Third-trimester maternal toxicity with nevirapine use in pregnancy. Obstet Gynecol 2005; 106 : $1032-8$

4. Joao E.C., Calvet G.A., Menezes J.A., et al. Nevirapine toxicity in a cohort of HIV-1-infected pregnant women. Am J Obstet Gynecol 2006;194:199-202.

5. Ministério da Saúde. Recomendações para Profilaxia da Transmissão Vertical do HIV e Terapia Anti-Retroviral em Gestantes. Brasília, 2006. <http://www.saude.rio.rj.gov.br/media/dstaids_consenso_ gestante_2006.pdf>

6. Mirochnick M., Siminski S., Fenton T., et al. Nevirapine pharmacokinetics in pregnant women and in their infants after in utero exposure. Pediatr Infect Dis J 2001;20:803-5.

7. Guay L.A., Musoke P., Fleming T., et al. Intrapartum and neonatal single-dose nevirapine compared with zidovudine for prevention of mother-to-child transmission of HIV-1 in Kampala, Uganda: HIVNET 012 randomised trial. Lancet 1999;354:795-802.

8. Marseille E., Kahn J.G., Mmiro F., et al. Cost effectiveness of single-dose nevirapine regimen for mothers and babies to decrease vertical HIV-1 transmission in sub-Saharan Africa. Lancet 1999;354:803-9.

9. de Maat M.M., ter Heine R., van Gorp E.C., et al. Case series of acute hepatitis in a non-selected group of HIV-infected patients on nevirapine-containing antiretroviral treatment. AIDS 2003; $17: 2209-14$.

10. Martinez E., Blanco J.L., Arnaiz J.A., et al. Hepatotoxicity in HIV-1-infected patients receiving nevirapine-containing antiretroviral therapy. AIDS 2001;15:1261-8.

11. de Maat M.M., ter Heine R., Mulder J.W., et al. Incidence and risk factors for nevirapine-associated rash. Eur J Clin Pharmacol 2003;59:457-62.

12. Ena J., Amador C., Benito C., Fenoll V., Pasquau F. Risk and determinants of developing severe liver toxicity during therapy with nevirapine-and efavirenz-containing regimens in HIVinfected patients. Int J STD AIDS 2003;14:776-81.

13. Martin A.M., Nolan D., James I., et al. Predisposition to nevirapine hypersensitivity associated with HLA-DRB $1 * 0101$ and abrogated by low CD4 T-cell counts. AIDS 2005;19:97-9.

14. Dieterich D.T., Robinson P.A., Love J., Stern J.O. Drug-induced liver injury associated with the use of nonnucleoside reversetranscriptase inhibitors. Clin Infect Dis 2004;38:S80-9. 
15. Bersoff-Matcha S.J., Miller W.C., Aberg J.A., et al. Sex differences in nevirapine rash. Clin Infect Dis 2001;32:124-9.

16. Fagot J.P., Mockenhaupt M., Bouwes-Bavinck J.N., et al. Nevirapine and the risk of Stevens-Johnson syndrome or toxic epidermal necrolysis. AIDS 2001;15:1843-8.

17. Gonzalez de Requena D., Nunez M., Jimenez-Nacher I., Soriano V. Liver toxicity caused by nevirapine. AIDS 2002;16:290-1.

18. Martin-Carbonero L., Nunez M., Gonzalez-Lahoz J., Soriano V. Incidence of liver injury after beginning antiretroviral therapy with efavirenz or nevirapine. HIV Clin Trials 2003;4:115-20.

19. Ministério da Saúde. Protocolo para a prevenção de transmissão vertical de HIV e sífilis. Brasília, 2006. <http:// w w w. s a u d e.rio.rj.gov.br/m e d i a / dstaids_gestante_protocolo_out06.pdf>

20. AIDS Clinical Trial Group. Table of grading severity of adverse experiences. Rockville (MD): Division of AIDS, National Institute of Allergy and Infectious Diseases, 1996.

21. Guidelines for the management of hepatic events with Viramune. Available: www.viramune.com. 2006.

22. Stern J.O., Robinson P.A., Love J., et al. A comprehensive hepatic safety analysis of nevirapine in different populations of HIV infected patients. J Acquir Immune Defic Syndr 2003;34:S21-33.

23. Nunez M., Lana R., Mendoza J.L., et al. Risk factors for severe hepatic injury after introduction of highly active antiretroviral therapy. J Acquir Immune Defic Syndr 2001;27:426-31.

24. Boehringer-Ingelheim Pharmaceuticals Inc. Viramune drug label. Revised September 4, 2003.

25. Centers for Disease Control and Prevention (CDC). Serious adverse events attributed to nevirapine regimens for postexposure prophylaxis after HIV exposures - worldwide, 1997-2000. MMWR Morb Mortal Wkly Rep 2001;49:1153-6.
26. Zhou J., Phanupak P., Kiertiburanakul S., et al. Highly active antiretroviral treatment containing efavirenz or nevirapine and related toxicity in the TREAT Asia HIV Observational Database. J Acquir Immune Defic Syndr 2006;43:501-3.

27. Wooltorton E. HIV drug nevirapine (Viramune): risk of severe hepatotoxicity. CMAJ 2004;170:1091.

28. Edwards S.G., Larbalestier N., Hay P., et al. Experience of nevirapine use in a London cohort of HIV-infected pregnant women. HIV Med 2001;2:89-91.

29. Jamisse L., Balkus J., Hitti J., et al. Antiretroviral-Associated Toxicity Among HIV-1-Seropositive Pregnant Women in Mozambique Receiving Nevirapine-Based Regimens. J Acquir Immune Defic Syndr 2007;44:371-6.

30. Lyons F., Hopkins S., McGeary A., et al. Nevirapine tolerability in HIV infected women in pregnancy - A word of caution. 2nd IAS conference on HIV Pathogenesis and Treatment. Paris, France. July 13-16, 2003 [abstract LB27].

31. Langlet P., Guillaume M.P., Devriendt J., et al. Fatal liver failure associated with nevirapine in a pregnant HIV patient: the first reported case. Gastroenterol 2000;118: Abstract 6623.

32. Kramer F., Stek A., Du W.B., Kovacs A. Nevirapine tolerability in HIV-infected women in pregnancy. Eleventh Conference on Retrovirus and Opportunistic Infections [abstract 923]; February 2004; San Francisco, California.

33. Natarajan U., Pym A., McDonald C., et al. Safety of nevirapine in pregnancy. HIV Med 2007;8:64-9.

34. Marazzi M.C., Germano P., Liotta G., et al. Safety of nevirapine-containing antiretroviral triple therapy regimens to prevent vertical transmission in an African cohort of HIV-1-infected pregnant women. HIV Med 2006; $7: 338-44$. 